\title{
Life-threatening endocrinologic paraneoplasia in an 83-year-old patient with solitary fibrous tumor of the pleura: a case report U Oehler*
}

Address: Institut für Pathologie, Hegau-Bodensee-Hochrheinkliniken, 78207 Singen, Germany

* Corresponding author

from 35te Tagung der Pathologen am Oberrhein/35th Meeting of Pathologists of the Upper Rhine Region (PATOR) The Institute of Pathology, University Hospital Freiburg, Germany. I July 2006

Published: I4 March 2007

Diagnostic Pathology 2007, 2(SuppI I):SI3 doi:I0.II86/I746-I596-2-SI-SI3

(c) 2007 Oehler; licensee BioMed Central Ltd.

\section{Case report}

An 83-year-old male patient with progressive alterations in behavior and aggressiveness was suspected of psychiatric disease. Loss of conscience led to hospital admission. The blood glucose was reduced to $11 \mathrm{~g} / 100 \mathrm{ml}$ and insulinoma could be clinically excluded.

5 months before, the patient had refused to be operated on for a large $(20 \mathrm{~cm})$ pleural tumor. Punch biopsy had revealed a solitary fibrous tumor. The hypoglycemia was regarded to be paraneoplastic due to IGF-II production, which is known to occur in about $5 \%$ of patients with this disease. As the condition got rapidly worse (the patient had to be wakened every hour at night due to hypoglycaemia), the patient finally agreed to surgery. During the operation, the blood glucose level rose to $200 \mathrm{mg} / 100 \mathrm{ml}$, and the patient is well since. The clinically problematic hypoglycemia, in this case, appears to be a matter of size of the tumor which had clinically grown during the past 5 months, whereas the lesion had been incidentally detected on a chest x-ray 37 years before in 1969, when the patient had also refused surgery.

The pathologist should be aware of this although rare complications in an otherwise non malignant tumor and inform the clinician. 